\section{Ocean acidification} disrupts induced defences in the intertidal gastropod Littorina littorea

\author{
Ruth Bibby ${ }^{1, \dagger}$, Polly Cleall-Harding ${ }^{1, \dagger}$, \\ Simon Rundle ${ }^{1, *}$, Steve Widdicombe ${ }^{2}$ \\ and John Spicer ${ }^{1}$
}

\author{
${ }^{1}$ Marine Biology and Ecology Research Centre, University of Plymouth, \\ Plymouth PL4 8AA, UK \\ ${ }^{2}$ Plymouth Marine Laboratory, Plymouth PL1 3DH, UK \\ *Author for correspondence (srundle@plymouth.ac.uk). \\ ${ }^{\dagger}$ Contributed equally to this paper.
}

Carbon dioxide-induced ocean acidification is predicted to have major implications for marine life, but the research focus to date has been on direct effects. We demonstrate that acidified seawater can have indirect biological effects by disrupting the capability of organisms to express induced defences, hence, increasing their vulnerability to predation. The intertidal gastropod Littorina littorea produced thicker shells in the presence of predation (crab) cues but this response was disrupted at low seawater $\mathrm{pH}$. This response was accompanied by a marked depression in metabolic rate (hypometabolism) under the joint stress of high predation risk and reduced pH. However, snails in this treatment apparently compensated for a lack of morphological defence, by increasing their avoidance behaviour, which, in turn, could affect their interactions with other organisms. Together, these findings suggest that biological effects from ocean acidification may be complex and extend beyond simple direct effects.

Keywords: phenotypic plasticity; climate change; marine gastropods; Littorina littorea

\section{INTRODUCTION}

Rising levels of atmospheric carbon dioxide are acidifying the world's oceans at a rate many times greater than under natural conditions; surface seawater $\mathrm{pH}$ is currently $0.1 \mathrm{pH}$ unit lower than pre-industrial values and is predicted to decrease by up to 0.4 units by the end of the century (Orr et al. 2005). Such chemical changes to the oceans from acidification could have major implications for marine life, in particular to those organisms that rely on the process of calcification for constructing their skeletons (Riebesell et al. 2000; Orr et al. 2005).

The calcification process in the oceans is disrupted by the effects of increased $\mathrm{CO}_{2}$ on carbonate chemistry; in effect, calcium carbonate skeletons can dissolve when seawater is undersaturated with respect to the relevant calcium carbonate mineral. As calcareous structures have a protective as well as a supportive role in several marine groups, such taxa will be more vulnerable to predation under low ocean
$\mathrm{pH}$. Such acidification-induced alterations to calcification could be particularly problematic where species exhibit phenotypic plasticity in their calcified defences (Agrawal 2001). Such induced defences are common and allow prey species to vary their defensive structures and behaviours, depending on the level of predation risk in their environment (Tollrian \& Harvell 1999). If such taxa were unable to express induced defences in environments with high predation risk, they could be more vulnerable to attack. Such indirect effects of ocean acidification are likely to add to those from direct effects but, so far, have not been investigated. Here we test whether the ability of an intertidal gastropod to produce induced defences is disrupted significantly by low $\mathrm{pH}$ conditions.

\section{MATERIAL AND METHODS}

We exposed individuals of the common periwinkle Littorina littorea obtained from Wembury Bay, South Devon $\left(50^{\circ} 18.98^{\prime} \mathrm{N}\right.$, $\left.4^{\circ} 05.10^{\prime} \mathrm{W}\right)$ to a factorial treatment of normal versus acidified seawater and the presence or absence of chemical cues from the predatory crab Carcinus maenas. Snails (mean shell length $11.9 \mathrm{~mm}$, s.d. $1.1 \mathrm{~mm}$ ) were grown individually $(60 \mathrm{ml}$ lidded plastic pots with $30 \times 5 \mathrm{~mm}$ holes in 81 experimental tanks) for 15 days in laboratory mesocosms supplied with either natural seawater (measured $\mathrm{pH}_{\mathrm{NBS}}$ : mean 7.97, range 7.97-8.02; mean total $\mathrm{CO}_{2} 1.21 \mathrm{mmol} \mathrm{l}^{-1}$, range 1.11-1.79) or seawater acidified by bubbling $\mathrm{CO}_{2}$ (nominal $\mathrm{pH}$ 6.45; measured $\mathrm{pH}_{\mathrm{NBs}}$ : mean 6.63, range 6.56-6.73; mean total $\mathrm{CO}_{2} 2.54 \mathrm{mmol}^{-1}$, range $2.37-$ 2.89). Note that care must be taken in comparing our $\mathrm{pH}$ measurements with those in other studies as, currently, there are four different $\mathrm{pH}$ scales; our measurements are all $\mathrm{pH}_{\mathrm{NBs}}$ (Bates 1973). Supply water was pumped at $9.4 \pm 0.5 \mathrm{ml} \mathrm{min}^{-1}$ (Watson Marlow 503S peristatic pumps) from reservoirs (450 1) containing seawater $\left(15^{\circ} \mathrm{C}, 35 \mathrm{psu}\right)$ from a recirculating system. Seawater acidification followed the methods described by Widdicombe \& Needham (2007) and is summarized here. $\mathrm{CO}_{2}$ gas was diffusebubbled into half of the reservoirs and was controlled via a computerized solenoid system (Walchem WebMaster-GI controller USA) that separately maintained each reservoir at a set temperature-compensated $\mathrm{pH}( \pm 0.01)$. The total $\mathrm{CO}_{2}$ content of seawater was measured using an automated $\mathrm{CO}_{2}$ analyser (CIBACorning $965, \mathrm{UK}) . \mathrm{pH}_{\mathrm{NBS}}$ in reservoirs was monitored using flat surface combination $\mathrm{pH}$ electrodes (Walchem S650CD USA, calibrated using precision Radiometer buffers) and was used to control the amount of $\mathrm{CO}_{2}$ added to the water. The $\mathrm{pH}$ of acidified reservoirs was set at $\mathrm{pH}_{\mathrm{NBS}}$ 6.45. As the water was extracted from the reservoirs to supply experimental aquaria, it was replaced with fresh seawater from the recirculating seawater system. Any resultant change in $\mathrm{pH}_{\mathrm{NBS}}$ of the reservoir water initiated $\mathrm{CO}_{2}$ addition, until $\mathrm{pH}_{\mathrm{NBS}}$ had returned to the preset value; the other two tanks were maintained as a control, equilibrated with $\mathrm{pCO}_{2}$ equivalent to normal air pressure. Within each of these $\mathrm{pH}$ treatments, half the snails were grown in aquaria with a crab. Growth trials were carried out in the mesocosm facility at the Plymouth Marine Laboratory.

Morphological plasticity was measured as the percentage change in shell thickness (on the growing edge at the lip of the shell adjacent to the whorl; accuracy to $0.0005 \mathrm{~mm}$ ) - a key trait that provides protection from predators (Trussell \& Smith 2000). Snails were photographed using a digital camera (Nikon coolpix 7900, 7.5 mega pixel) aperture upwards on a scaled background. The images were analysed using the image analysis program IMAGEJ $(1.34 \mathrm{~s})$.

We also measured rates of oxygen uptake $\left(\mathrm{MO}_{2}\right)$ by snails on completion of growth trials, to assess how treatments had affected individual physiologies. Closed bottle respirometry experiments were used to determine $\mathrm{MO}_{2}$ directly following the completion of growth trails. All snails were kept in the water treatments that they were subjected to during their growth trails in blacked out $60 \mathrm{ml}$ pots. The amount of $\mathrm{O}_{2}$ consumed was measured for 1 hour following an acclimation period (also 1 hour); the pots were sealed with a water-tight screw lid, which was placed on the pot while it remained submerged in the 81 tank. A Strathkelvin $781 \mathrm{O}_{2}$ electrode, thermostated at $15^{\circ} \mathrm{C}$, was used to measure the water $\mathrm{PO}_{2}$. The electrode was standardized using aerated seawater as $100 \%$ saturation, and sodium sulphite dissolved in seawater as $0 \%$ saturation. After an hour, samples of the seawater from each respirometry pot were taken using a $1 \mathrm{ml}$ syringe, which was then passed over the electrode in the thermostated jacket. $\mathrm{MO}_{2}$ (expressed as $\mathrm{ml} \mathrm{g}^{-1} \mathrm{~h}^{-1}$ ) for each individual at $15^{\circ} \mathrm{C}$ in seawater 
Table 1. Results of statistical tests assessing differences between four experimental treatments. (Shell thickness data were analysed using a two-way ANOVA followed by post hoc pairwise comparison (figure 1) and those for $\mathrm{MO}_{2}$ and behavioural avoidance response using a non-parametric Kruskal-Wallis test with a Mann-Whitney $U$-test used to test for pairwise differences between treatments.)

\begin{tabular}{|c|c|c|c|}
\hline treatment & d.f. & statistic & $p$ \\
\hline \multicolumn{4}{|l|}{ shell thickness } \\
\hline $\mathrm{pH}$ & 1 & $F=6.3$ & $<0.05$ \\
\hline cue & 1 & $F=5.1$ & $<0.05$ \\
\hline $\mathrm{pH}^{*}$ cue & 1 & $F=8.4$ & $<0.005$ \\
\hline \multicolumn{4}{|l|}{$\%$ shell thickness } \\
\hline $\mathrm{pH}$ & 1 & $F=6.6$ & $<0.05$ \\
\hline cue & 1 & $F=10.2$ & $<0.005$ \\
\hline $\mathrm{pH}^{*}$ cue & 1 & $F=7.6$ & $<0.05$ \\
\hline \multicolumn{4}{|l|}{$\mathrm{MO}_{2}$} \\
\hline overall (Kruskal-Wallis) & 32 & $H=31.0$ & $<0.001$ \\
\hline $\begin{array}{l}\text { normal } \mathrm{pH}+\text { cue versus low } \\
\mathrm{pH}+\text { cue }\end{array}$ & 32 & $U=46$ & $<0.005$ \\
\hline low $\mathrm{pH}$ versus low $\mathrm{pH}+$ cue & 32 & $U=169$ & $<0.005$ \\
\hline behavioural response & & & \\
\hline overall (Kruskal-Wallis) & 32 & $H=20.4$ & $<0.001$ \\
\hline $\begin{array}{l}\text { normal } \mathrm{pH} \text { versus normal } \mathrm{pH}+ \\
\text { cue }\end{array}$ & 32 & $U=328$ & $<0.005$ \\
\hline low $\mathrm{pH}$ versus normal $\mathrm{pH}+$ cue & 32 & $U=288$ & $<0.005$ \\
\hline normal $\mathrm{pH}$ versus low $\mathrm{pH}+$ cue & 32 & $U=363$ & $<0.05$ \\
\hline $\begin{array}{l}\text { normal } \mathrm{pH}+\text { cue versus low } \\
\mathrm{pH}+\text { cue }\end{array}$ & 32 & $U=210$ & $<0.005$ \\
\hline
\end{tabular}

at a salinity of $35_{\mathrm{PSU}}$ was calculated by comparing the $\mathrm{PO}_{2}$ of a control pot in each 81 tank with the $\mathrm{PO}_{2}$ of each pot containing a snail.

Finally, we quantified the avoidance behaviour of snails on completion of the growth trials as this form of defence could be used to compensate for poor morphological defences (Rundle et al. 2004). Individuals were returned to their treatment tanks and pots overnight before behavioural trials. These trials were performed in circular, polypropene pots (diameter $=16 \mathrm{~cm}$, height $=6 \mathrm{~cm}$ ) with a $4 \mathrm{~cm}$ length of $5 \mathrm{~cm}$ diameter polypropene tubing cut in half and glued down onto the centre of the pot to create a 'refuge' area. The pots contained $500 \mathrm{ml}$ seawater of $\mathrm{pH}_{\mathrm{NBS}} 8.06$ at $15^{\circ} \mathrm{C}$. The snails were placed in the centre of their pot, next to the refuge, and left to acclimatize for $50 \mathrm{~min}$. Following acclimation, their position was noted every $5 \mathrm{~min}$ for an hour after the addition of $50 \mathrm{ml}$ of trial water (either cue or non-cue). Cue water was prepared through the addition of an individual $C$. maenas (carapace width $71 \pm 5 \mathrm{~mm}$ ) into 51 of aerated seawater for a 48 hours period prior to the trial. The individuals were exposed to trial water of cue and non-cue (seawater) in an alternate fashion (subsequent analyses demonstrated no effect of trial order on responses). We used 'crawl out', i.e. the percentage of time spent above or at the water surface, as a measure of avoidance response (Rundle et al. 2004).

We used a two-way analysis of variance (ANOVA) to test for differences between $\mathrm{pH}$ (low versus high) and cue (present versus absent) treatments and their interaction, followed by a Tukey test to check for pairwise differences between treatments. Following data transformations ( $\log _{10}$ or, for percentage data, arcsin) we used Levene's test to check that the data did not exhibit significant heterogeneity. As behavioural and respirometry data did not conform to this test we used a Kruskal-Wallis test to look for differences between treatments in these parameters, followed by a Mann-Whitney $U$-test to check for significant pairwise differences.

\section{RESULTS AND DISCUSSION}

Acidification had a clear influence on induced morphological defences in the form of shell thickness. There were significant separate effects of $\mathrm{pH}$ and cue treatments, and their interaction (table 1) on the actual amount of shell thickening and after
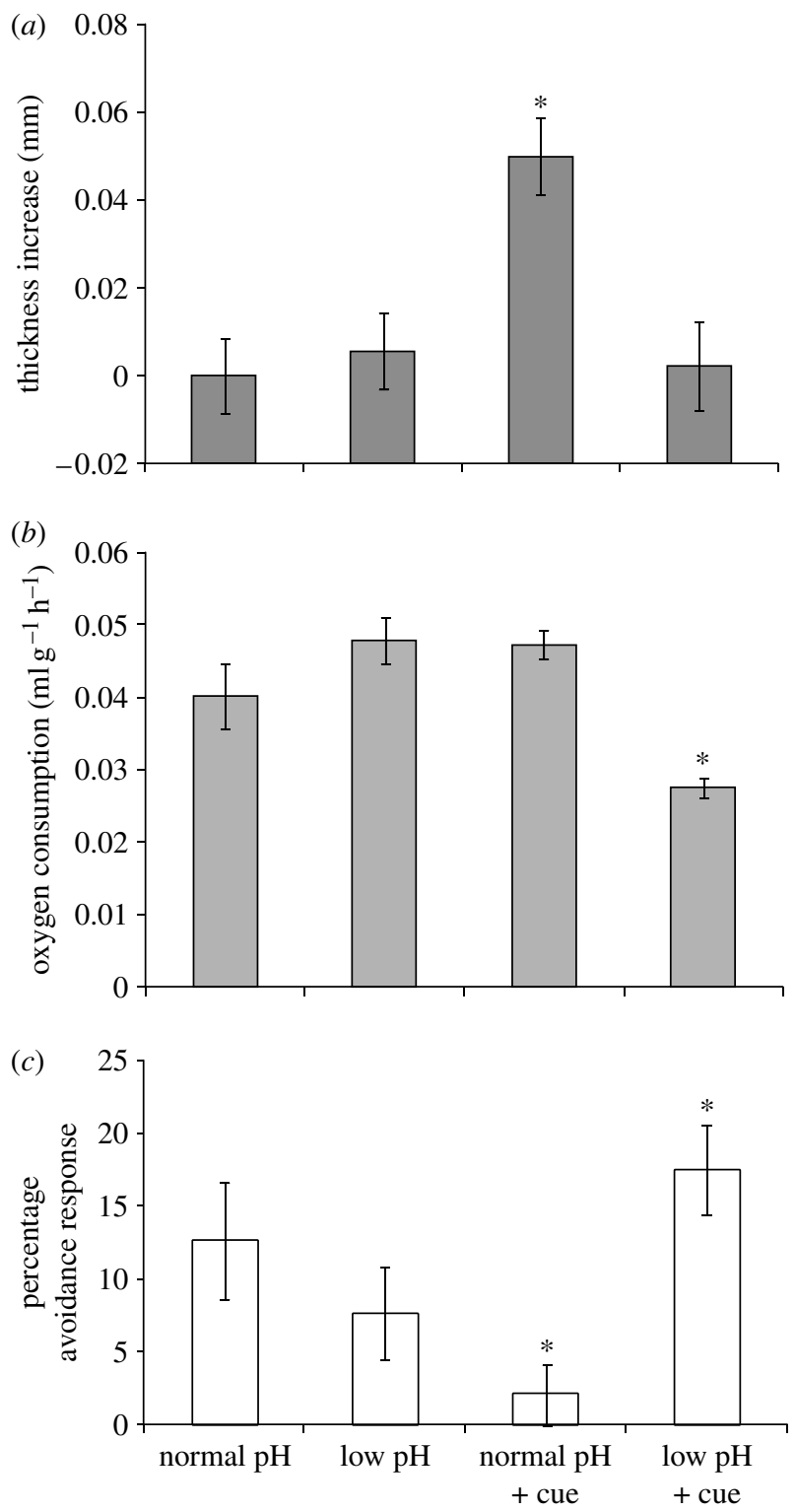

Figure 1. Responses of $L$. littorea to treatments of different $\mathrm{pH}_{\mathrm{NBS}}$ values (normal versus low) and predator (crab) cues (presence versus absence). (a) The percentage increase in shell thickness over the trial period. (b) Metabolism estimated as $\mathrm{MO}_{2}$ over a 1 hour period following trials. (c) The behavioural avoidance (percentage of time a snails spent above or at the water surface in trials) shown following the addition of cues from a predatory crab. Asterisks indicate treatments that are significantly different from (a) all other treatments, (b) treatments other than normal $\mathrm{pH}$ or $(c)$ each other and all other treatments, as identified either by (a) ANOVA followed by pairwise comparisons or $(b, c)$ Kruskal-Wallis tests followed by pairwise Mann-Whitney $U$-tests.

standardizing for thickness at the start of trials. Post hoc pairwise tests demonstrated that those snails grown in the presence of crab cues in seawater of normal $\mathrm{pH}$ grew significantly thicker during the experiment compared with those in the other three treatments, both in terms of actual and standardized (i.e. percentage) increased thickening (figure $1 a$; table 1). On average, snails exposed to crab cues increased their shell thickness by approximately $0.05 \mathrm{~mm}$, whereas those from the other three treatments showed virtually no change in shell thickness 
(figure $1 a$ ). As the average thickness of snails across treatments at the end of the trial was $0.16 \mathrm{~mm}$, the extra growth in the cue treatment represents a substantial contribution to this potential form of induced defence. Poor expression of this trait through disruption by low seawater $\mathrm{pH}$ could have implications for the survival of some gastropod species if they are unable to maintain sufficient protection against crushing predators. Further work is needed, however, before we will be able to fully gauge the fitness implications of such impaired induced defences.

Measurements of $\mathrm{MO}_{2}$ on completion of the trials suggested that the reduction in induced morphological defences in snails exposed to predation cues and acidification stress could have been explained, in part, by the physiological response of snails in this treatment (figure $1 b$ ). These snails had a significantly lower $\mathrm{MO}_{2}$ compared with those in other treatments (figure $1 b$; table 1 ) and so may have effectively 'shut down' (hypometabolism) under the joint stress of low $\mathrm{pH}$ and high-predation risk (Pörtner et al. 2004).

There was also an apparent link between induced morphological responses and the level of avoidance behaviour exhibited by snails. Those animals exposed to crab cues in normal seawater exhibited a significantly lower level of behavioural avoidance compared with all other treatments, including those exposed to crabs in acidified seawater (figure $1 c$; table 1), which suggests compensation for a lack of morphological, induced defence through an increased behavioural response. Contrasting directional responses for morphological and behavioural traits have been demonstrated previously and suggest that animals may trade-off one form of defence against the other (Rundle et al. 2004). Such increased avoidance responses have implications for many taxa: although they may reduce the chances of predation, they mean that organisms spend less time performing other important activities such as feeding. As gastropods such as L. littorea are often highly abundant in intertidal habitats, where they play an important role as grazers, a reduction in their grazing activity could have major ramifications for the trophic dynamics of rocky shore ecosystems including trait-mediated indirect interactions (Peacor \& Werner 2001).

Taken together, our findings suggest that ocean acidification could have major implications for marine ecosystems through indirect effects on taxa that rely on calcification for the production of induced defences. Although we have limited our study to just one species there is relevance to other calcifying organisms including other molluscs (both planktonic and benthic) and planktonic taxa like coccolithophorids. The investigation of the interaction between acidification and induced defences in other taxa would provide important insights into just how widespread this phenomenon might be and if some groups are more susceptible than others.

We thank Julie Soane for technical support for respirometry experiments and Hazel Needham for advice and assistance during the running of growth trials. Thanks to financial support from the Natural Environment Research Council, the UK Department of Trade and Industry and the UK Department of Environment, Food and Rural Affairs for their help in building the seawater acidification system.

Agrawal, A. A. 2001 Phenotypic plasticity in the interactions and evolution of species. Science 294, 321-325. (doi:10. 1126/science.1060701)

Bates, R. G. 1973 Determination of $\mathrm{pH}$, theory and practice, p. 479. New York, NY: Wiley-Interscience.

Orr, J. C. et al. 2005 Anthropogenic ocean acidification over the twenty-first century and its impact on calcifying organisms. Nature 437, 681-686. (doi:10.1038/nature 04095)

Peacor, S. D. \& Werner, E. E. 2001 The contribution of trait-mediated indirect effects to the net effects of a predator. Proc. Natl Acad. Sci. USA 98, 3904-3908. (doi:10.1073/pnas.071061998)

Pörtner, H. O., Langenbuch, M. \& Reipschläger, A. 2004 Biological impacts of elevated ocean $\mathrm{CO}_{2}$ concentrations: lessons from animal physiology and earth history. F. Oceanogr. 60, 705-718. (doi:10.1007/s10872004-5763-0)

Riebesell, U., Zondervan, I., Rost, B., Tortell, P. D., Zeebe, R. E. \& Morel, F. M. M. 2000 Reduced calcification of marine plankton in response to increased atmospheric $\mathrm{CO}_{2}$. Nature 407, 364-367. (doi:10.1038/35030078)

Rundle, S. D., Spicer, J. I., Coleman, R. A., Vosper, J. \& Soane, J. 2004 Environmental calcium modifies induced defences in snails. Proc. $R$. Soc. $B$ 271, S67-S70. (doi:10.1098/rsbl.2003.0106)

Tollrian, R. \& Harvell, C. D. 1999 The ecology and evolution of induced defences, p. 383. Princeton, NJ: Princeton University Press.

Trussell, G. C. \& Smith, L. D. 2000 Induced defences in response to an invading crab predator: an explanation of historical and geographical phenotypic change. Proc. Natl Acad. Sci. USA 97, 2123-2127. (doi:10.1073/pnas. 040423397)

Widdicombe, S. \& Needham, H. R. 2007 Impact of $\mathrm{CO}_{2}$ induced seawater acidification on the burrowing activity of Nereis virens and sediment nutrient flux. Mar. Ecol. Prog. Ser. 341, 111-122. (doi:10.3354/meps341111) 